\title{
DEVELOPMENT AND CHARACTERIZATION OF TASTE MASKED ORODISPERSIBLE FILM OF CHLORPROMAZINE HYDROCHLORIDE
}

\author{
UZMA BARKAT $^{1,4}$, SUMERA LATIF $^{1 *}$, HAFSA AFZAL $^{1}$, NASIR ABBAS ${ }^{2}$, \\ SHAISTA QAMAR ${ }^{3}$, RAHAT SHAMIM ${ }^{2}$ and AMJAD HUSSAIN ${ }^{2}$ \\ ${ }^{1}$ Institute of Pharmacy, Faculty of Pharmaceutical and Allied Health Sciences, \\ Lahore College for Women University, Jail Road, Lahore, Pakistan \\ ${ }^{2}$ University College of Pharmacy, University of the Punjab, Lahore, Pakistan \\ ${ }^{3}$ Institute of Pharmaceutical Sciences, \\ University of Veterinary and Animal Sciences, Lahore, Pakistan \\ ${ }^{4}$ Drug Regulatory Authority of Pakistan, Lahore, Pakistan
}

\begin{abstract}
Thin-film drug delivery, also referred to as orodispersible film has emerged as an advanced alternative to the traditional tablets, capsules, and liquids. The present work investigates the improvement in solubility to have a rapid onset of action, and palatability of chlorpromazine hydrochloride (CPZ) by developing an orodispersible film (ODF) using the solvent casting method. CPZ indicated for the control of nausea and vomiting, and in the treatment of schizophrenia in adults and children, has low bioavailability $(30-50 \%)$ when taken orally as a tablet due to extensive first-pass metabolism. Moreover, it is very bitter and has an unpleasant after-taste. In this study, seven placebo formulations were prepared containing different concentrations of film-forming polymers (hydroxypropyl methylcellulose E5 and polyvinyl pyrrolidone K30) and plasticizers (propylene glycol and glycerin), and the most suitable polymer-plasticizer combination was screened to obtain required physical properties. CPZ loaded film was made using an optimized polymer-plasticizer combination employing sucralose and menthol as taste-masking agents. Drug-loaded films were transparent, smooth, and disintegrated in $14.67 \pm 1.53 \mathrm{sec}$. Films showed a folding endurance of $>400$, tensile strength of $1.54 \pm 0.11 \mathrm{~N} / \mathrm{mm}^{2}$ and percentage elongation of $18.7 \% \pm 0.50$ suggesting good mechanical strength. More than $90 \%$ drug release was obtained within 3 min in dissolution media. FTIR analysis displayed no significant interactions between drug and polymer. The film was also found palatable with a sweet taste by human volunteers. Hence the taste-masked films of CPZ can be a potential alternative to conventional oral dosage forms and may also enhance patient compliance.
\end{abstract}

Keywords: Chlorpromazine $\mathrm{HCl}$, orodispersible film, solvent casting, HPMC E5, sucralose, taste masking, in vivo taste evaluation, patient compliance

The oral route of drug administration is among the most preferred routes due to its convenience, cost-effectiveness, acceptability, and a high degree of patient compliance. However, conventional oral solid dosage forms have some problems associated with them like the first-pass effect, difficulty in swallowing, and fear of choking especially in pediatric and geriatric patients. Bedridden, nauseous, unconscious, and non-compliant patients also have limitations for the usage of the traditional oral solid dosage forms (1).

Another detrimental reason for nonadherence to medication therapy is the bitter taste of drugs and unpleasant after taste which may result in failure to achieve desired outcomes in concerned patients. Although many solid oral dosage forms (e.g., tablets and capsules) have the advantage of masking or encapsulating bitter taste, such means have been proved futile for many children because they often cannot or will not swallow tablets or capsules. Liquid formulations typically are used between 6 and 8 years of age but there is great variation in the ability of older children (also teenagers and adults) to swallow tablets and capsules (2).

Recently, fast-dissolving drug delivery systems gained the interest of pharmaceutical technologists as an alternate approach to conventional oral solid dosage forms. The development of Oral Strip Technology has attracted much attention amongst the fast drug releasing systems. A film that rapidly disintegrates in the oral cavity is generally called an orodispersible film (ODF) as termed by European

* Corresponding author: e-mail: sumera_latif@hotmail.com 
Medicines Agency (EMA) or simply as oral soluble film according to US FDA $(3,4)$. This newer drug delivery system consists of a very thin film or strip usually of the size of a postage stamp and when placed on the tongue or any oral mucosal tissue, gets hydrated on coming in contact with saliva, adheres to the site of application, and rapidly disintegrates and dissolves to release the drug for oromucosal or/ and intragastric absorption. ODFs also address swallowing issues encountered with pediatric and geriatric patients and can be effectively used in various medical conditions like motion sickness, allergic attack, acute pain, and acute coughing where a rapid onset of action is desired. The oral and sublingual drug delivery via ODF also has the potential to lower the dosing and improve the onset of action. ODFs increase patient compliance as they are easy to carry, can even be taken in conditions when there is no access to water and may enhance patient acceptability by virtue of improvement in the taste of bitter drugs $(5,6)$.

Chlorpromazine hydrochloride (CPZ) being one of the antipsychotic drugs included in the World Health Organization's List of Essential Medicines (2019) was selected as a model drug (7). Other than its antipsychotic uses, CPZ is indicated for the control of nausea and vomiting, is recommended in intractable hiccups, and for relief of restlessness before surgery. It is now mainly used in the treatment of schizophrenia in adults and children. Marketed preparations of CPZ include tablets $(10,25,50$, and $100 \mathrm{mg})$ and IV/IM injection $(25 \mathrm{mg} / \mathrm{mL})(8,9)$. CPZ has low oral bioavailability $(30-50 \%)$ due to extensive first-pass metabolism. Moreover, it is very bitter and has an after taste (10-12). Figure 1 represents the chemical structure of $\mathrm{CPZ}$.

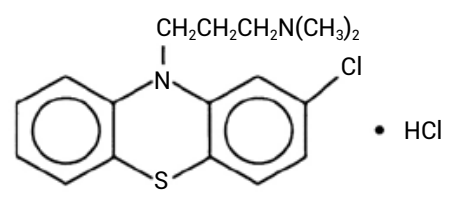

Figure 1. Chemical structure of Chlorpromazine $\mathrm{HCl}$

The proposed study was aimed to develop ODF of CPZ by solvent casting method to enhance its clinical outcomes and improve palatability, especially in pediatric and elderly patients. Firstly, placebo films were prepared using different concentrations of film-forming polymers (hydroxypropyl methylcellulose E5 and polyvinyl pyrrolidone K30) and plasticizers (propylene glycol and glycerin), and later the most suitable polymer-plasticizer combination, imparting film the required physical properties, was screened. Then CPZ loaded ODFs were made using an optimized polymer-plasticizer combination employing sucralose and menthol as taste-masking agents. Prepared ODFs were delineated for physicochemical and mechanical properties. Taste concealing was determined by in vivo taste evaluation using human volunteers. Based on a five-point scale for taste evaluation, the developed ODF was found to be palatable and acceptable by the human volunteers.

\section{EXPERIMENTAL}

\section{Materials}

Chlorpromazine $\mathrm{HCl}$ was purchased from XABC Biotech Co., Ltd., China. All other chemicals were obtained from different sources; Hydroxypropyl methylcellulose E5 (HPMC E5), polyvinyl pyrrolidone (PVP K-30), propylene glycol (PG) and glycerin (Hangzhou Zhongbao Import and Export Corporation, China), sucralose (Techno (Fujian) Food Ingredients Co, China), menthol (Shanghai Polar Bear Pharmaceutical Co., China), and citric acid, ethanol, hydrochloric acid $(\mathrm{HCl})$, sodium hydroxide $(\mathrm{NaOH})$ and sodium chloride $(\mathrm{NaCl})$, potassium dihydrogen phosphate, disodium hydrogen phosphate (Merck Darmstadt Germany). All chemicals and solvents used were of analytical grade.

\section{Preparation of placebo film}

The solvent casting method was employed for the casting of ODF formulations (F1-F7) without the drug (13). Placebo films were formulated using polymers HPMC E5 and PVP K30 and the plasticizers PG and glycerin alone and in combination (Table 1). In this context, the polymer was dissolved in the solvent (with continuous stirring for one hr) followed by the addition of a plasticizer. The final volume was made up to $50 \mathrm{~mL}$ with the solvent (Table 1) and the film solution was sufficiently de-aerated to remove all the entrapped air bubbles. Suitable volume $(10 \mathrm{~mL})$ was cast onto glass Petri plates of uniform sizes and dried in the oven at $45^{\circ} \mathrm{C}$ for four hr or till a dry film was formed.

The most suitable placebo formulation was selected based on the transparency, smoothness, and peelability (14). Different volumes $(7,8,9,10 \mathrm{~mL})$ of the selected placebo formulation were then cast onto the Petri plates. Films were investigated for appearance, peelability, smoothness, handling, and disintegration time (Table 2) to identify the most appropriate volume for drug loading. 
Table 1. Composition and physical properties of placebo film formulations.

\begin{tabular}{|c|c|c|c|c|c|c|c|}
\hline \multicolumn{8}{|c|}{ Formulations } \\
\hline Ingredients & FI & $\mathrm{F} 2$ & F3 & F4 & F5 & F6 & F7 \\
\hline HPMC E5 (g) & 2.2 & 2.2 & 1.1 & 2.2 & 1 & 1 & 1 \\
\hline PVP K30 (g) & & & & & 0.5 & 0.5 & 0.5 \\
\hline PG $(\mathrm{g})$ & 0.4 & & 0.7 & 1.4 & & 0.5 & 0.5 \\
\hline Glycerin (g) & & 0.4 & 0.8 & 1.5 & 0.5 & & 0.5 \\
\hline Ethanol (mL) & & & & 10 & 20 & 50 & \\
\hline Water $(\mathrm{mL})$ & 50 & 50 & 50 & 50 & 50 & & 50 \\
\hline $\begin{array}{l}\text { Physical } \\
\text { properties } \\
\text { of films }\end{array}$ & $\begin{array}{c}\text { Transparent, } \\
\text { smooth, not } \\
\text { peelable }\end{array}$ & $\begin{array}{c}\text { Transparent, } \\
\text { smooth, not } \\
\text { peelable }\end{array}$ & $\begin{array}{c}\text { Transparent, } \\
\text { smooth, not } \\
\text { peelable }\end{array}$ & \begin{tabular}{|c|} 
Transparent, \\
Smooth, \\
peelable
\end{tabular} & $\begin{array}{l}\text { Semi-transparent, } \\
\text { rough, difficult } \\
\text { to peel }\end{array}$ & $\begin{array}{l}\text { Opaque, } \\
\text { rough, not } \\
\text { peelable }\end{array}$ & $\begin{array}{l}\text { Opaque, } \\
\text { rough, not } \\
\text { peelable }\end{array}$ \\
\hline
\end{tabular}

Table 2. Evaluation of the physical properties and disintegration time of films obtained after casting different volumes of the selected placebo formulation.

\begin{tabular}{|c|c|c|c|c|}
\hline \multirow{2}{*}{ Parameters } & \multicolumn{4}{|c|}{ Volume casted into Petri plate (mL) } \\
\cline { 2 - 5 } & 7 & 8 & 9 & 10 \\
\hline Physical properties & $\begin{array}{c}\text { Transparent, smooth, } \\
\text { difficult to peel }\end{array}$ & $\begin{array}{c}\text { Transparent, } \\
\text { smooth, peelable }\end{array}$ & $\begin{array}{c}\text { Transparent, } \\
\text { smooth, peelable }\end{array}$ & $\begin{array}{c}\text { Transparent, } \\
\text { smooth, peelable }\end{array}$ \\
\hline Handling & Poor & Satisfactory & Satisfactory & Satisfactory \\
\hline Disintegration time (sec) & 13 & 24 & 42 & 55 \\
\hline
\end{tabular}

\section{Preparation of drug-loaded films}

To prepare drug-loaded films, the selected polymer in varying concentrations as shown in Table 3 was dissolved in $30 \mathrm{~mL}$ of distilled water with continuous stirring for one hr (Solution 1). $\mathrm{CPZ}$ was added to this solution and mixed till completely dissolved. Sucralose and citric acid were added to this solution and mixed well. Accurately weighed quantities of PG and glycerin were dissolved separately in $10 \mathrm{~mL}$ of ethanol and $1 \mathrm{~mL}$ of menthol ( $1 \%$ ethanolic solution) was added to it (Solution 2). Solution 2 was added to Solution 1 and volume was made up to $50 \mathrm{~mL}$ with distilled water. The $\mathrm{pH}$ of the final solution was adjusted to 6.2 by adding few drops of $0.1 \mathrm{M} \mathrm{NaOH}$ (15) followed by sonication for one hr to remove all entrapped air bubbles.

The selected volume of the film solutions was cast onto glass Petri plates of area $59.42 \mathrm{~cm}^{2}$ (the quantity of the drug was calculated accordingly to have $25 \mathrm{mg}$ of $\mathrm{CPZ} / \mathrm{film} / 4 \mathrm{~cm}^{2}$ ) and allowed to dry in the oven at $40^{\circ} \mathrm{C}$ for $5 \mathrm{hr}$. The films were carefully removed from the Petri plate and checked for any imperfections. Films were cut according to the size required (square film: $2 \mathrm{~cm}$ length, $2 \mathrm{~cm}$ width). The best formulation was chosen based on the physical appearance, peelability, folding endurance, and disintegration time (Table 3). This final film was investigated for various physical and mechanical tests, in vitro dissolution, and taste masking (16).

\section{Characterization of ODFs of CPZ Physical appearance}

The appearance of the ODFs $(\mathrm{n}=10)$ was evaluated by visual observation. Films were measured regarding thickness at five points (four corners and center) using a micrometer screw gauge. Films with nicks or bubbles or those with a mean thickness variation of greater than $5 \%$ were excluded from the analysis $(4,5)$.

\section{Weight variation and surface $\mathrm{pH}$}

The uniformity of weight of ODFs $(n=20)$ was checked by weighing each ODF. Surface $\mathrm{pH}$ measurement was performed at room temperature by adding $4 \mathrm{~mL}$ distilled water on the top of the film $\left(2 \times 2 \mathrm{~cm}^{2}\right)$ contained in a petri dish. After the film was completely disintegrated, the $\mathrm{pH}$ of the solution was determined by $\mathrm{pH}$ meter (14) and the average of three determinations was calculated.

\section{Disintegration test}

A disintegration test was performed by placing the ODF in a Petri dish containing $10 \mathrm{~mL}$ of distilled water. The Petri dish was swirled clockwise manually after every $10 \mathrm{sec}$. The time taken by the ODF to disintegrate was noted and a mean of three determinations was taken (14).

\section{Folding endurance test}

The folding endurance test is an indication of the brittleness of the film. The folding endurance was 
Table 3. Composition and physical evaluation of ODFs of CPZ.

\begin{tabular}{|c|c|c|c|c|}
\hline \multicolumn{5}{|c|}{ Formulation } \\
\hline Ingredients & FA & FB & FC & FD \\
\hline CPZ (g) & 2.321 & 2.321 & 2.321 & 2.321 \\
\hline HPMC E5 (g) & 1 & 1.5 & 2.0 & 2.5 \\
\hline PG (g) & 1.4 & 1.4 & 1.4 & 1.4 \\
\hline Glycerin (g) & 1.5 & 1.5 & 1.5 & 0.25 \\
\hline Sucralose (g) & 0.25 & 0.25 & 0.25 & 0.20 \\
\hline Citric acid (g) & 0.20 & 0.20 & 0.20 & 1 \\
\hline $\begin{array}{c}1 \% \text { Ethanolic solution } \\
\text { of menthol (mL) }\end{array}$ & 1 & 1 & 10 & 10 \\
\hline Ethanol (mL) & 10 & 10 & 50 & 50 \\
\hline Water (mL) & 50 & 50 & Transparent, peelable & Transparent, peelable \\
\hline Physical properties & Transparent, difficult & Transparent, difficult & to peel & Satisfactory \\
\hline Handling & Low & Low & Satisfactory & $>400$ \\
\hline Folding endurance & 150 & 300 & $>400$ & 42 \\
\hline Disintegration time (sec) & 10 & 12 & 17 & \\
\hline
\end{tabular}

determined by folding the film sample at the same place till the film breaks or visible cracks are developed. It is expressed as the number of times the film can be folded without breaking (1).

\section{Tensile strength and percent elongation}

Tensile strength is the maximum stress applied to a point at which the film specimen ruptures. The tensile strength of the film was tested to assess the elasticity and strength of the film formulation (1). European Standard EN ISO 527-3 guidelines were followed to determine tensile strength (17). The film free from bubbles or imperfections was placed between two clamps held $50 \mathrm{~mm}$ apart using Tensile Strength Tester (Lloyd Instruments, UK) and pulled at a rate of $5 \mathrm{~mm} / \mathrm{min}$. The measurements were performed in triplicate and tensile strength was determined as per the following equation

Tensile Strength $=\frac{\text { Force at break }(\mathrm{N})}{\text { Cross }- \text { sectional area }\left(\mathrm{mm}^{2}\right)}$

To determine percentage elongation, the distance between the grips of the tensile strength tester was measured before and after the fracture of the film on applying force (1). The percentage elongation of the film was calculated using the formula

$$
\text { Percentage Elongation }=\frac{\mathrm{D}_{f}-\mathrm{D}_{o}}{\mathrm{D}_{o}} \times 100
$$

where,

$\mathrm{D}_{o}=$ Distance between the grips before fracture of the film.

$\mathrm{D}_{f}=$ Distance between the grips after fracture of the film

\section{Uniformity of content}

The uniformity of contents of the films $(n=10)$ was determined by immersing ODF in a $100 \mathrm{~mL}$ volumetric flask containing $2 \mathrm{~mL}$ of ethanol and $60 \mathrm{~mL}$ of $0.1 \mathrm{M} \mathrm{HCl}$. The solution was sonicated for $15 \mathrm{~min}$ and volume was made up to $100 \mathrm{~mL}$ with $0.1 \mathrm{M} \mathrm{HCl}$. After suitable dilutions with $0.1 \mathrm{M} \mathrm{HCl}$, the absorbance was measured by UV/Visible spectrophotometer (U-2800 BMS, UK) at $254 \mathrm{~nm}$. The percent drug content in each film was calculated by comparing the absorbance of the film with a standard solution of pure CPZ.

\section{Drug content analysis}

A sample of ODFs $\left(2 \times 2 \mathrm{~cm}^{2}\right)$ equivalent to $250 \mathrm{mg}$ of CPZ was placed in a $500 \mathrm{~mL}$ volumetric flask containing $10 \mathrm{~mL}$ of ethanol and $300 \mathrm{~mL}$ of $0.1 \mathrm{M} \mathrm{HCl}$. The solution was shaken for $15 \mathrm{~min}$ and volume was made up to $500 \mathrm{~mL}$ with $0.1 \mathrm{M} \mathrm{HCl}$. The solution was filtered followed by further dilution with $0.1 \mathrm{M} \mathrm{HCl}$. Drug content was determined by comparing absorbance with a standard solution of the pure drug as described above (18).

\section{In vitro dissolution study}

In vitro drug release studies were performed in three media i.e., $0.1 \mathrm{M} \mathrm{HCl}$, phosphate buffer $\mathrm{pH} 6.8$, and distilled water (volume: $500 \mathrm{~mL}$; temperature: $37 \pm 0.5^{\circ} \mathrm{C}$ ) in USP Type II (Paddle type) dissolution apparatus at $50 \mathrm{rpm}$. Sample aliquots $(5 \mathrm{~mL})$ were withdrawn at predetermined time intervals $0.5,1,2$, $3,4,5$, and $10 \mathrm{~min}$, and the same volume of the medium was reinstated after each withdrawal to maintain 
the sink conditions. Samples were analyzed by UV/ Visible spectrophotometer at $254 \mathrm{~nm}$ after appropriate dilutions. Percent release of the drug was calculated from the standard curve (concentration range: $2-12 \mu \mathrm{g} / \mathrm{mL}$ ). The drug release data were also fitted to various kinetic models like Zero order, First order, Higuchi, Korsmeyer-Peppas, and Hixson-Crowell using DD Solver free add-in extension for MS Excel ${ }^{\circledR}$ (19) to establish the best fit model $(20,21)$.

\section{Fourier transform infrared (FT-IR) spectroscopy}

Infrared spectra of CPZ, HPMC E5, and the drug-loaded film were obtained to determine the drug-polymer interactions if any by using FT-IR Spectrophotometer (Alpha Bruker, UK). The scanning range was 4000 to $400 \mathrm{~cm}^{-1}$.

\section{Differential scanning calorimetry (DSC)}

DSC thermograms of pure drug, polymer, drug-polymer physical mixture, and film were obtained to get information about the thermal behavior and physical characteristics of the drug. Samples were placed in alumina crucibles in a nitrogen atmosphere. The differential scanning calorimeter (SDT Q-600, TA Instruments, USA) was run at a constant heating rate of $15^{\circ} \mathrm{C} / \mathrm{min}$ with a nitrogen flow of $100 \mathrm{~mL} / \mathrm{min}$ over a temperature range.

\section{Taste evaluation of ODFs of CPZ}

The taste evaluation study protocol was approved by the Institutional Ethical Review Committee, Lahore College for Women University, Lahore, Pakistan (Reference No. Dir/LCWU/157A). Film formulation was evaluated in twelve healthy human volunteers who were asked to gargle the mouth with $200 \mathrm{~mL}$ of water before the test. The volunteers were instructed to place the film $\left(2 \times 2 \mathrm{~cm}^{2}\right)$ on the tongue until complete disintegration occurred and to score taste evaluation parameters of the film as per Table 4 . Then the volunteers were asked to spit the sample and rinse the mouth with $200 \mathrm{~mL}$ of water $(5,22)$.

\section{RESULTS AND DISCUSSION}

In the current study, the solvent casting method was employed to form ODFs of CPZ. Literature has shown the solvent casting method as the most commonly used method for preparing ODFs because of certain advantages over other methods $(13,23)$.

\section{Selection of placebo formulation}

Seven placebo formulations were prepared using film formers and plasticizers either alone or in combination and assessed for peelability and physical appearance (Table 1). Previous studies have revealed that PVP K30 when used alone did not prove to be a good film former owing to the formation of films that were difficult to peel. Therefore, PVP K30 was used in combination with HPMC E5. Contrary, HPMC E5 alone gave better films compared to that made with a combination of HMPC E5 and PVP K30 in terms of peelability and transparency. This finding is consistent with the previous literature using HPMC E5 as a film former (14). It was also noticed that formulations employing PG and glycerin (plasticizers) in combination gave better film properties compared to the formulations in which either PG or glycerin was used as a plasticizer. Hence, formulation F4 containing 4.4\% w/v HPMC E5 and 5.8\% w/v total plasticizer concentration $(2.8 \% \mathrm{w} / \mathrm{v}$ PG plus $3 \% \mathrm{w} / \mathrm{v}$ glycerin) was selected for drug loading.

Then different volumes $(7,8,9$, and $10 \mathrm{~mL})$ of the formulation F4 were cast to select the most suitable volume resulting in desirable physical properties (Table 2). It was observed that films made by casting $7 \mathrm{~mL}$ volume were difficult to peel and handle. Casting $8 \mathrm{~mL}, 9 \mathrm{~mL}$, and $10 \mathrm{~mL}$ volumes gave better physical properties but the disintegration time of the films was found to be increased (24, 42, and $55 \mathrm{sec}$ respectively) with an increase in volume. Hence based on the physical properties and disintegration time, $8 \mathrm{~mL}$ volume was chosen for casting the drug-loaded films since disintegration time of less than $30 \mathrm{sec}$ was a desirable film property (22).

Table 4. Taste evaluation score criteria.

\begin{tabular}{|c|c|c|c|c|}
\hline Taste & After taste & Acceptability & Mouthfeel & Score \\
\hline Very bitter & Very bitter & Very poor & Gritty, irritating & 1 \\
\hline Bitter & Bitter & Poor & Gritty & 2 \\
\hline Slightly bitter & Slightly bitter & Acceptable & Smooth & 4 \\
\hline Slightly sweet & Slightly sweet & Good & Very smooth & 5 \\
\hline Sweet & Sweet & Very good & & 4 \\
\hline
\end{tabular}


Formulation selection of drug-loaded films

Four formulations of drug-loaded films (FA, FB, FC, FD) were made by varying the polymer concentration and keeping plasticizer concentration constant (Table 3) to select the polymer concentration that will impart the film a disintegration time of less than $30 \mathrm{sec}$ and required folding endurance. The study disclosed that disintegration time and folding endurance increased with increasing polymer concentration and was found to be in line with previously reported literature (24). Formulations FA and FB gave films which were difficult to peel (Figure 2) and their folding endurance was also less. Formulations FC and FD appeared to have good physical properties, a folding endurance greater than 400, and a disintegration time of 17 and $42 \mathrm{sec}$ (Table 3) respectively. Therefore, formulation FC (Figure 2) was picked for further investigation of the film properties and taste masking.

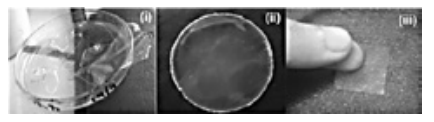

Figure 2. (i) Film (FB) not peelable in one piece; (ii) Film (FC) easily peeled from the Petri plate; (iii) $\mathrm{ODF}$ of $\mathrm{CPZ}\left(2 \times 2 \mathrm{~cm}^{2}\right)$ held between fingertips.

\section{Characterization of drug-loaded ODFs}

Table 5 represents the various physical and mechanical properties of CPZ film. On visual inspection, films were transparent, smooth, and flexible. The thickness of ODFs $(n=10)$ was determined at five locations. The thickness of individual locations ranged from $0.12-0.17 \mathrm{~mm}$. The mean of five locations ranged from $0.13-0.16 \mathrm{~mm}$ (Table 5). Weight of ODFs $(n=20)$ ranged from $85-91 \mathrm{mg}$ while the mean weight was $87.8 \mathrm{mg} \pm 1.64$. Thickness and uniformity of weight of ODFs manifest the uniformity of dose distribution in the ODFs. The mean surface $\mathrm{pH}$ of ODFs $(\mathrm{n}=3)$ was $6.44 \pm 0.03$. The $\mathrm{pH}$ of a buccal mucosal surface is about 6.8. Too acidic or alkaline $\mathrm{pH}$ of film formulation can irritate the buccal mucosa. The mean surface $\mathrm{pH}$ of the ODFs was fairly close to the $\mathrm{pH}$ of buccal mucosa suggesting that the ODF of CPZ can be safely administered into the oral cavity without causing irritation (25). Mean disintegration time was $14.67 \pm 1.53 \mathrm{sec}$. Disintegration time is directly related to the drug dissolution. An early disintegration of the film aids in faster dissolution. In CPZ film, a fast disintegration can be attributed to citric acid which acts as a saliva stimulating agent and can further improve the disintegration time of the film (26).

Folding endurance indicates the brittleness or flexibility of the film. The ability of the film to bear folding up to 300 times is considered satisfactory for good ODFs (1). ODFs of CPZ had a folding endurance of greater than 400 showing that the film was tough and had good flexibility (Table 5) and also in agreement with previously reported studies (4).

The tensile strength of ODFs is important to resist mechanical stress during production, storage, transportation, handling, and application. ODFs should ideally possess high percent elongation and moderate tensile strength (1). The ODFs of CPZ had a mean tensile strength of $1.54 \mathrm{~N} / \mathrm{mm}^{2} \pm 0.10$ and percent elongation of $18.7 \% \pm 0.46$. These findings were comparable with the previous studies (14). The prepared film had a content uniformity of $96.65-101.36 \%$ while the drug content was found to be $99.84 \% \pm 1.55$ based on the assay. These results indicated that the drug was uniformly distributed in the film (Table 5).

\section{In vitro dissolution study}

Figure 3 compares the in vitro drug release profile of the CPZ loaded ODFs in three media (phosphate buffer $\mathrm{pH} 6.8,0.1 \mathrm{M} \mathrm{HCl}$, and distilled water) at time intervals of $0.5,1,2,3,4,5$, and $10 \mathrm{~min}$. It was

Table 5. Evaluation parameters of ODFs of CPZ.

\begin{tabular}{|c|c|c|c|}
\hline Parameter & Mean $\pm \mathrm{SD}$ & Min & $\operatorname{Max}$ \\
\hline Thickness $(\mathrm{mm})(\mathrm{n}=10)$ & $0.15 \pm 0.01$ & 0.13 & 0.16 \\
\hline Weight variation $(\mathrm{mg})(\mathrm{n}=20)$ & $87.8 \pm 1.64$ & 85 & 91 \\
\hline Surface $\mathrm{pH}(\mathrm{n}=3)$ & $6.44 \pm 0.03$ & 6.41 & 6.46 \\
\hline Disintegration time $(\mathrm{sec})(\mathrm{n}=3)$ & $14.67 \pm 1.53$ & 13 & 16 \\
\hline Folding endurance $(n=3)$ & $>400 \pm 0$ & $>400$ & $>400$ \\
\hline Percentage elongation $(\%)(n=3)$ & $18.7 \pm 0.50$ & 18.2 & 19.2 \\
\hline Tensile strength $\left(\mathrm{N} / \mathrm{mm}^{2}\right)(\mathrm{n}=3)$ & $1.54 \pm 0.11$ & 1.44 & 1.66 \\
\hline Content uniformity (drug content $\%)(n=10)$ & $99.33 \pm 1.90$ & 95.65 & 101.36 \\
\hline Assay $(\%)(n=3)$ & $98.84 \pm 1.55$ & 98.17 & 101.22 \\
\hline
\end{tabular}


Table 6. Dissolution profile of ODFs of CPZ in different media.

\begin{tabular}{|c|c|c|c|c|c|c|c|c|c|}
\hline \multirow{2}{*}{$\begin{array}{c}\text { Time } \\
(\mathrm{mins})\end{array}$} & \multicolumn{3}{|c|}{$\begin{array}{c}\text { Drug release (\%) in phosphate } \\
\text { buffer pH } 6.8\end{array}$} & \multicolumn{3}{c|}{ Drug release (\%) in 0.1 M HCl } & \multicolumn{3}{c|}{ Drug release (\%) in distilled water } \\
\cline { 2 - 10 } & Mean \pm SD (n $=6)$ & Min & Max & Mean \pm SD (n=6) & Min & Max & Mean \pm SD (n =6) & Min & Max \\
\hline 0.5 & $9.67 \pm 0.87$ & 8.59 & 10.68 & $16.77 \pm 0.93$ & 15.70 & 18.01 & $22.56 \pm 1.80$ & 19.82 & 24.82 \\
\hline 1 & $25.51 \pm 1.21$ & 23.96 & 27.53 & $78.73 \pm 2.38$ & 75.60 & 81.68 & $73.20 \pm 2.89$ & 68.27 & 76.72 \\
\hline 2 & $85.21 \pm 2.90$ & 80.34 & 88.12 & $96.67 \pm 1.03$ & 95.49 & 98.19 & $84.74 \pm 1.87$ & 81.56 & 86.85 \\
\hline 3 & $99.26 \pm 1.12$ & 97.55 & 100.51 & $98.37 \pm 0.83$ & 97.33 & 99.70 & $90.68 \pm 1.91$ & 87.37 & 92.33 \\
\hline 4 & $100.87 \pm 1.12$ & 98.93 & 102.07 & $99.99 \pm 0.99$ & 98.27 & 101.03 & $98.58 \pm 1.46$ & 96.78 & 100.64 \\
\hline 5 & $100.49 \pm 1.11$ & 98.43 & 101.60 & $99.80 \pm 0.96$ & 98.15 & 100.76 & $99.44 \pm 1.21$ & 97.78 & 100.77 \\
\hline 10 & $100.04 \pm 1.05$ & 98.34 & 101.18 & $99.30 \pm 0.91$ & 98.03 & 100.30 & $99.09 \pm 1.06$ & 97.52 & 100.34 \\
\hline
\end{tabular}

Table 7. Release kinetics modeling of ODFs of CPZ.

\begin{tabular}{|c|c|c|c|c|c|}
\hline \multirow{2}{*}{ Medium } & \multicolumn{5}{|c|}{$\mathrm{R}^{2}$ - value } \\
\cline { 2 - 6 } & Zero Order & First Order & Higuchi & Hixon-Crowell & Korsmeyer-Peppas \\
\hline Phosphate buffer pH 6.8 & 0.8476 & 0.8362 & 0.7816 & 0.8905 & 0.8759 \\
\hline $0.1 \mathrm{M} \mathrm{HCl}$ & 0.1900 & 0.8277 & 0.7026 & 0.8675 & 0.7098 \\
\hline Distilled water & 0.1769 & 0.8931 & 0.7846 & 0.8865 & 0.7966 \\
\hline
\end{tabular}

found that more than $95 \%$ drug release was obtained within $3 \mathrm{~min}$ in all three media (Table 6). The salivary $\mathrm{pH}$ of normal individuals ranges from 6.2 to 7.4. The drug release profile in the phosphate buffer pH 6.8 was of prime interest since it depicts the drug release from ODF in the oral cavity. It can be seen that the initial drug release from the ODF was slow i.e. $9.67 \% \pm 0.87$ in $30 \mathrm{sec}$ and $25.51 \% \pm 1.21$ within $1 \mathrm{~min}$ which is possibly due to the time taken by the polymer to get hydrated followed by subsequent dissolution and release of the drug from the ODF in phosphate buffer $\mathrm{pH} 6.8$ (25).

Hixon-Crowell model best fitted in phosphate buffer $\mathrm{pH} 6.8$ and $0.1 \mathrm{M} \mathrm{HCl}$ suggesting that drug diffusion depends on the surface area of the ODF (Table 7). Results have shown a change in surface

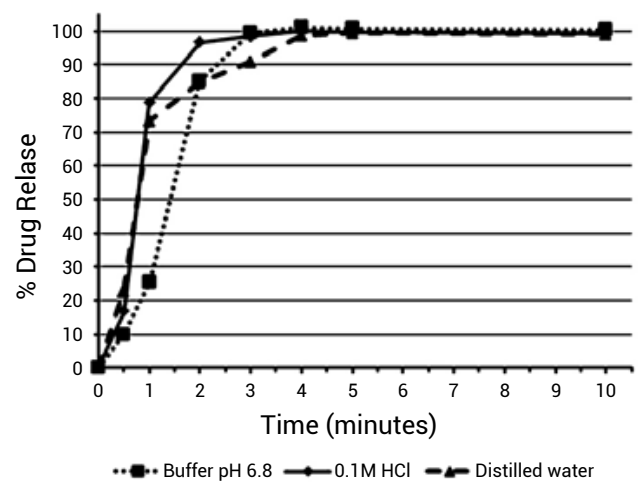

Figure 3. Comparison of in vitro drug release profile of ODFs of $\mathrm{CPZ}$ in different media. area with the progressive dissolution of matrix as a function of time. It can be attributed to the fact that on coming in contact with the dissolution medium the film polymer first hydrates and subsequently the drug dissolves as a result of film disintegrations in the medium (25). It further suggested that the drug release rate from the ODF is dependent on the dissolution of drug particles and not on drug diffusion from the film (20). In distilled water, the film followed the first order kinetic model which means that drug release from ODF is concentration-dependent (Table 7).

Fourier Transform Infrared (FT-IR) spectroscopy

The possible interaction between $\mathrm{CPZ}$ and HPMC E5 was investigated by infrared spectroscopy. Infrared spectra of pure CPZ, HPMC E5, and drugloaded film are shown in Figure 4. Drug spectrum

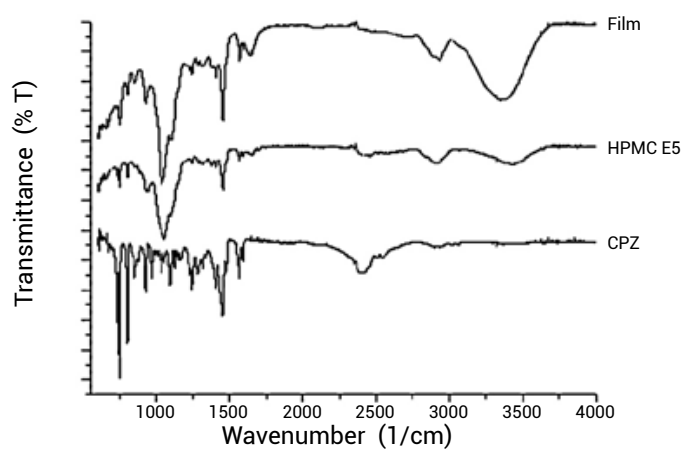

Figure 4. FT-IR spectrum of CPZ pure drug, HPMC E5 and CPZ film. 


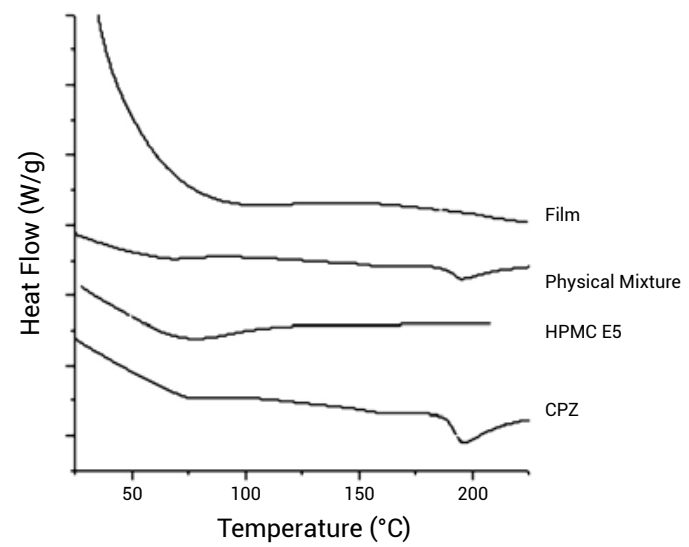

Figure 5. DSC thermograms of CPZ pure drug, HPMC E5, physical mixture and $\mathrm{CPZ}$ film.

shows characteristic absorption peaks at $2933.62 \mathrm{~cm}^{-1}$ (aliphatic $\mathrm{C}-\mathrm{H}$ stretching), $2394.12 \mathrm{~cm}^{-1}$ (indicating $\mathrm{H} 3 \mathrm{C}-\mathrm{NH}^{+}$stretching and combination mode), $1564.21 \mathrm{~cm}^{-1}$ (indicating phenyl ring vibrational mode), $1456.31 \mathrm{~cm}^{-1}$ (C-H deformational mode) and $750.37 \mathrm{~cm}^{-1}$ (aromatic $\mathrm{C}-\mathrm{H}$ bending mode) $(27,28)$. HPMC E5 exhibits principal peaks at $3500-3400 \mathrm{~cm}^{-1}$ (OH stretching), $2990 \mathrm{~cm}^{-1}$ (methyl and hydroxypropyl group stretching), $2550-2500 \mathrm{~cm}^{-1}$ (OH stretching), 1300-1250 $\mathrm{cm}^{-1}$ epoxide (cyclic C-O-C), 1100$1000 \mathrm{~cm}^{-1}$ (stretching vibrations of $\mathrm{C}-\mathrm{O}-\mathrm{C}$ group), $1000-950 \mathrm{~cm}^{-1}$ (pyranose ring). Approximately the same absorption peaks of CPZ and HPMC E5 are present in the spectrum of the film suggesting no significant interactions between drug and polymer $(29,30)$.

\section{Differential Scanning Calorimetry}

Figure 5 shows DSC thermograms of pure CPZ, HPMC E5, drug-polymer physical mixture, and film. A broad shoulder endotherm with a peak temperature at $198^{\circ} \mathrm{C}$ is shown for both pure $\mathrm{CPZ}$ and its physical mixture with HPMC E5 indicating that the pure drug was in a crystalline state. On the other hand, no melting peak was observed for the drug-loaded film. This disappearance of the endothermic peak indicated that $\mathrm{CPZ}$ is present in an amorphous or a dissolved state in the prepared film due to crystallization inhibition by HPMC E5 $(22,30,31)$.

\section{Taste evaluation}

Results of taste evaluation parameters including taste, after taste, mouthfeel, and overall acceptability are depicted in Figure 6. Taste evaluation parameters were scored based on the scoring criteria given in Table 4 and taste evaluation was performed according to the protocol approved by the Institutional Ethical Review Committee. Results showed that the

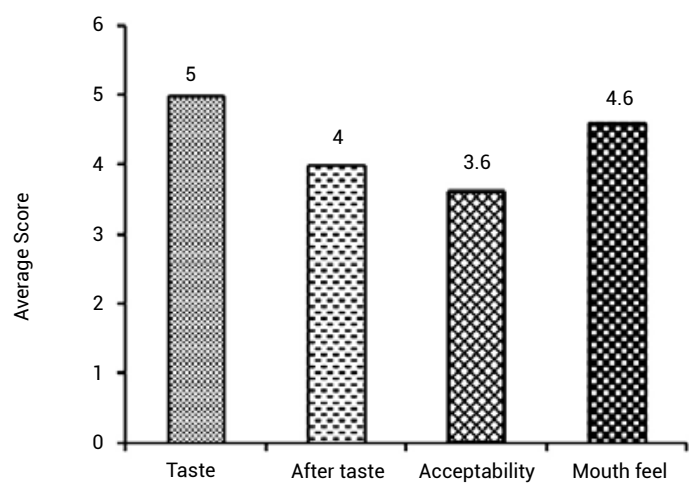

Figure 6. Taste evaluation of ODFs of CPZ by human volunteers $(\mathrm{n}=12)$.

mean score for the taste of ODF was 5 signifying that the taste sensed by human volunteers was sweet. Mouthfeel and after taste got scores of 4.6 and 4 and found to be smooth and slightly sweet. In terms of overall acceptability, the ODFs were scored between acceptable and good.

Hence CPZ was successfully developed in ODF by solvent casting technique employing HPMC E5 as polymer and PG and glycerin as plasticizers. The prepared ODFs showed desirable physical and mechanical properties (like folding endurance, tensile strength, and percent elongation), uniformity of drug content, and in vitro drug release. A disintegration time of less than half a minute was successfully achieved. Moreover, ODFs were found to be palatable and acceptable by the majority of volunteers crediting to the selected polymer-plasticizer combination, sucralose, and menthol.

\section{CONCLUSION}

It can be concluded that $\mathrm{CPZ}$ ODF can prove a potential drug dosage form in the pharmaceutical market because it can enhance the onset of action for CPZ in the treatment of emesis and schizophrenia. It can also increase compliance among the patient population.

\section{Conflicts of interest}

The authors declare no conflict of interest.

\section{REFERENCES}

1. Wasilewska K., Winnicka K.: Acta Pharm. 69, 155 (2019).

2. Mennella J.A., Spector A.C., Reed D.R., Coldwell S.E.: Clin. Ther. 35, 1225 (2013). 
3. Committee for Medicinal Products for Human Use, and Committee for Medicinal Products for Human Use, Guideline on the investigation of bioequivalence, European Medicines Agency (EMA), London 2010.

4. Alipour S., Akbari S., Ahmadi F.: Trends Pharm. Sci. 1, 25 (2015).

5. Liew K.B., Tan Y.T.F., Peh K.K.: AAPS PharmSciTech. 13, 134 (2012).

6. Singh S., Virmani T., Virmani R., Kumar P., Mahlawat G.: Univers. J. Pharm. Res. 3, 60 (2018).

7. World Health Organization, World Health Organization Model List of Essential Medicines, 21st List, World Health Organization, Geneva 2019.

8. Gudas G.K., Manasa B., Rajesham V.V., Kumar S.K., Kumari J.P.: J. Pharm. Sci. Tech. 2, 99 (2010).

9. Bethesda M.D.: AHFS Drug Information 2010. p. 2514, American Society of Health-System Pharmacists, 2010.

10. Halayqa M., Domańska U.: Int. J. Mol. Sci. 15, 23909 (2014).

11. https://pubchem.ncbi.nlm.nih.gov/ compound/6240 (accessed on 05.03.2016).

12. Haraguchi T, Okuno T, Nishikawa H., Kojima H., Ikegami S., et. al.: Chem. Pharm. Bull. 67, 1271 (2019).

13. Senta-Loys Z., Bourgeois S., Pailler-Mattei C., Agusti G., Briançon S., Fessi H.: J. Pharm. Pharmacol. 69, 582 (2017).

14. Ali M., Vijendar C., Kumar S., Krishnaveni J.: J. Pharmacovigilance 4, 210 (2016).

15. Jeong H.J., Chang I.H., Kim D.G., Lee J.H., Um J.H., et. al.: United States Patent Application Publication No.: US20150025084 A1 (2015).

16. Kumar R.S., Yagnesh T.N.S.: J. Drug Deliv. Ther. 9, 492 (2019).
17. International Standard, Plastics - Determination of tensile properties - Part 3: Test conditions for films and sheets (ISO 527-3:2018), International Organization for Standardization, Switzerland 2018.

18. British Pharmacopoeia Commission, British Pharmacopoeia 2016, Vol. III, p. 312, The Stationery Office, London 2016.

19. Zhang Y., Huo M., Zhou J., Zou A., Li W., et. al.: AAPS J. 12, 263 (2010).

20. Costa P., Lobo J.M.S.: Eur. J. Pharm. Sci. 13, 123 (2001).

21. Dash S., Murthy P.N.: Acta Pol. Pharm. 67, 217 (2010).

22. El Meshad A.N., El Hagrasy A.S.: AAPS PharmSciTech. 12, 1384 (2011).

23. Serrano D.R., Fernandez-Garcia R., Mele M., Healy A.M., Lalatsa A.: Pharmaceutics 11, 369 (2019).

24. Mushtaque M., Muhammad I.N., Hassan S.M.F., Ali A., Masood R.: Pak. J. Pharm. Sci. 33, 183 (2020).

25. Jadhav Y.G., Galgatte U.G., Chaudhari P.D.: Adv. Pharm. Bull. 8, 721 (2018).

26. Alayoubi A., Haynes L., Patil H., Daihom B., Helms R., Almoazen H.: Pharm. Dev. Technol. 7, 1 (2016).

27. Naini Y., Ahmad T.J., Kouassi G.K., Ananda S., Gowda N.M.M.: Am. J. Chem. 2, 181 (2012).

28. Govender T., Choonara Y.E., Kumar P., Du Toit L.C., Modi G., et. al.: Polymers 7, 1145 (2015).

29. Zayed G.M., Abd-ElRasoul S., Ibrahim M.A., Saddik M.S., Alshora D.H.: Saudi Pharm. J. 28, 266 (2020).

30. Reddy P.S., Murthy K.V.R.: Indian J. Pharm. Educ. Res. 52, 398 (2018).

31. Shaik F., Karnatham P., Dugganpalli R., Panga S., Akepati L.P.: Res. J. Pharm. Tech. 13, 3553 (2020). 